\title{
Challenges in ophthalmic pathology: The vitreoretinal membrane biopsy
}

\begin{abstract}
The introduction of vitreoretinal microsurgery has produced a new type of biopsy; that of the vitreoretinal membrane. This review investigates methods by which these scar-like tissues are handled in the laboratory and explores the implications of the results of such evaluations. The study of vitreoretinal membrane biopsies has provided much information concerning the pathobiology of the various conditions which may give rise to the tissue as well as insights into how membranes themselves develop. Moreover, the application of new laboratory techniques is expected to enhance our understanding of the formation of vitreoretinal membranes, and lead to further advances in their surgical and medical management.
\end{abstract}

Key words Age-related macular degeneration, Epiretinal membrane, Proliferative diabetic retinopathy, Proliferative vitreoretinopathy, Retina, Subretinal membrane, Vitreous, Wound healing

It is well over a century since the first descriptions of pathological cellular or connective tissue membranes in the vitreous (e.g. see review by Parsons 1905). ${ }^{1}$ Until quite recently, however, these tissues could generally only be observed during the morphological examination of enucleated eyes. The advent of closed, ${ }^{2}$ and to a lesser extent 'open-sky', ${ }^{3}$ vitreoretinal surgery has permitted sampling of membranes within the vitreous and also from beneath the neuroretina (including neovascular membranes in conditions such as age-related macular degeneration) in patients. Thus a relatively new type of biopsy material has been born. The membranes arising on the inner retinal surface have become known as epiretinal membranes $^{1}$ (or, if from the macular region, as epimacular membranes) ${ }^{4}$ while those from beneath the neuroretina have been called subor retro-retinal membranes. Epiretinal membranes may extend within or onto the detached posterior vitreous (posterior hyaloid membrane) in the event of a posterior vitreous
PAUL HISCOTT, DAVID WONG, IAN GRIERSON detachment. ${ }^{5}$ Sheets or strands crossing the vitreous are sometimes called transvitreous membranes. Anteriorly, membranes can arise in, or be continuous with, the vitreous base and even extend as far as the posterior iris surface or pupil.

Biopsies of pathological tissue are usually undertaken to establish a diagnosis.

Vitreoretinal biopsies also may be for diagnostic purposes as, for example, in the case of intraocular lymphoma, but such conditions are rare and tend not to produce membranes.

Conversely, in the conditions which do produce membranes the diagnosis is seldom in doubt. Why, then, attempt laboratory studies of vitreoretinal membranes? Laboratory findings from the membranes may have a number of uses, for example providing 'feed-back' to the surgeon concerning surgical dissection planes (see below). However, the principal objective of these investigations is to improve our understanding of the pathogenesis of vitreoretinal membranes, and of the many disorders which cause them (the most important of which include proliferative diabetic retinopathy (PDR), the complication of rhegmatogenous retinal detachment known as proliferative vitreoretinopathy (PVR) and agerelated macular degeneration (ARMD)). Thus it is anticipated that logical management strategies for vitreoretinal membranes will be developed. Indeed, previous studies have shown that vitreoretinal membrane formation represents an attempt at wound healing, chiefly by non-neural cells from the retina (see reviews by Grierson and colleagues). ${ }^{6,7}$ Nevertheless, although the membranes contract like scars (hence causing retinal problems such as folding or detachment), they differ from cutaneous wounds in that the repair process in vitreoretinal membranes is protracted and disorganised. ${ }^{8}$ Moreover, although inflammation probably plays an important part in initiating membrane formation, the dearth of inflammatory cells in many established membranes suggests that, unlike skin wounds, these cells are not so important in the orchestration of subsequent vitreoretinal membrane evolution. ${ }^{9,10}$ In addition,
P. Hiscott

D. Wong

I. Grierson

Unit of Ophthalmology Department of Medicine University of Liverpool Liverpool; UK

and

St Paul's Eye Unit Royal Liverpool University Hospital

Liverpool, UK

P. Hiscott

Department of Pathology University of Liverpool Liverpool, UK

Paul Hiscott

Unit of Ophthalmology Department of Medicine University Clinical Departments

Duncan Building

Daulby Street

Liverpool L69 3GA, UK

Tel: +44 (0)151706 4912 Fax: +44 (0)151 7065802 e-mail: paulsh@liv.ac.uk

Received: 11 October 1999 Accepted without revision: 10 February 2000 
vitreoretinal membranes often are still cellular after months of development. These observations have led to clinical trials with cytotoxic drugs (including daunomycin and 5-fluorouracil) as adjuncts to membranectomy, with the object of preventing membrane recurrence. ${ }^{11,12}$ Furthermore, a variety of peptides and proteins have been described in the tissues and some of these molecules have been suggested as potential targets for therapeutic intervention (e.g. TGF-beta). ${ }^{13,14}$

By nature, biopsies of these membranes are usually much smaller than biopsies obtained from the ocular surface or adnexa. Moreover, the membrane tissue typically is translucent or pale in colour and diaphanous in nature. Furthermore, some membranes adhere tenaciously to almost any surface. Such characteristics render the specimens difficult to see and handle in the laboratory.

Our review aims to explore some of the options available in the handling of membrane specimens and to provide examples of the use of these specimens in research and in diagnostic pathology.

\section{Acquisition of specimens}

The pathologist or researcher new to vitreoretinal membranes initially may find it helpful to observe surgical vitreoretinal procedures firsthand before handling membrane specimens in the laboratory. The benefits of such observation include a better understanding of the nature of the tissue (which will assist in the handling of specimens) and an idea of the sorts of questions likely to be asked of the biopsy.

Most vitreous and periretinal membrane specimens are removed from the eye on the end of one of the instruments (e.g. intraocular forceps) used during the vitrectomy and then transferred to a fixative or a transport medium. If a disposable instrument, such as a bent needle, is employed, the surgeon sometimes places the instrument together with attached membrane into the specimen container. Occasionally, fragmented membranes are retrieved from the aspirated infusion fluid.

Membrane specimens are most often 'lost' between their collection in the eye and their arrival in the laboratory. Reasons for such a mishap include: 1. The specimen was not transferred from the surgical instrument to the fluid in the specimen container. Sometimes membranes become dislodged from the forceps as the specimen passes through the sclerotomy at the pars plana (a difficulty which may be evaded by employing modified forceps: e.g. vitreous specimens can be successfully retrieved with non-crushing cupped foreign body forceps). ${ }^{15}$ In addition, membranes which are easily visualised peroperatively may not be so easy to see once they are outside the eye. This problem is compounded when the membrane is adherent to the instrument and when debris is present in the specimen collection fluid (which may give the erroneous appearance of a successful transfer of tissue from instrument to fluid).

2. The specimen is so small and pale that it cannot be distinguished from debris in the collection fluid.

3. Small specimens are also at risk of drying out if not quickly placed in fixative or other medium after removal. Dried-out specimens are easily lost.

4. The specimen has become lodged in the lid of the container or between the lid and the top of the container during transport to the laboratory.

To improve the success rate in the acquisition of tissue, the collection method can be modified in a variety of ways:

1. The use of a small bottle (e.g. small glass bottles with screw-on tops) containing only $2-5 \mathrm{ml}$ of collection fluid improves visualisation of the specimen and reduces the amount of fluid in which it can hide.

2. The collection fluid may be filtered before use to reduce the amount of residual debris.

3. Ensure that the specimen is placed in fixative or other medium quickly after removal from the eye.

4. Small translucent specimens which have been placed in a fixative for morphological assessment (see below) are sometimes more easily visualised if minute amounts of ink or dye (e.g. Indian ink, methylene blue) are added to the fixative while the membrane is still in the fluid. The ink particles or dye often stick to or stain the membrane so that the specimen becomes more visible. However, it is important to add the ink or dye in tiny increments so that the fixative fluid remains translucent.

5. If the specimen cannot be seen despite the above manoeuvres, check the lid and the gap between container and lid. Decanting the fluid into a wide receptacle, so that the fluid layer becomes very shallow, may also help.

If the specimen still cannot be found it was probably too small to provide useful information anyway!

\section{Options in the laboratory investigation of vitreoretinal membrane biopsies}

There are a number of options available for the laboratory study of vitreoretinal membrane biopsies (Fig. 1) and to some extent the selection depends on the question being asked of the tissue. Commonly, inquiries arise about either the composition of the specimen or the functional status of the cells in the tissue.

\section{Membrane composition}

Vitreoretinal membranes are characteristically heterogeneous in composition: important information may be obtained by evaluating the distribution of various components within a membrane and by making comparisons between different membranes. ${ }^{16,17}$ Moreover, as we have seen, the specimens are usually small and often difficult to see in fluid media. For these 


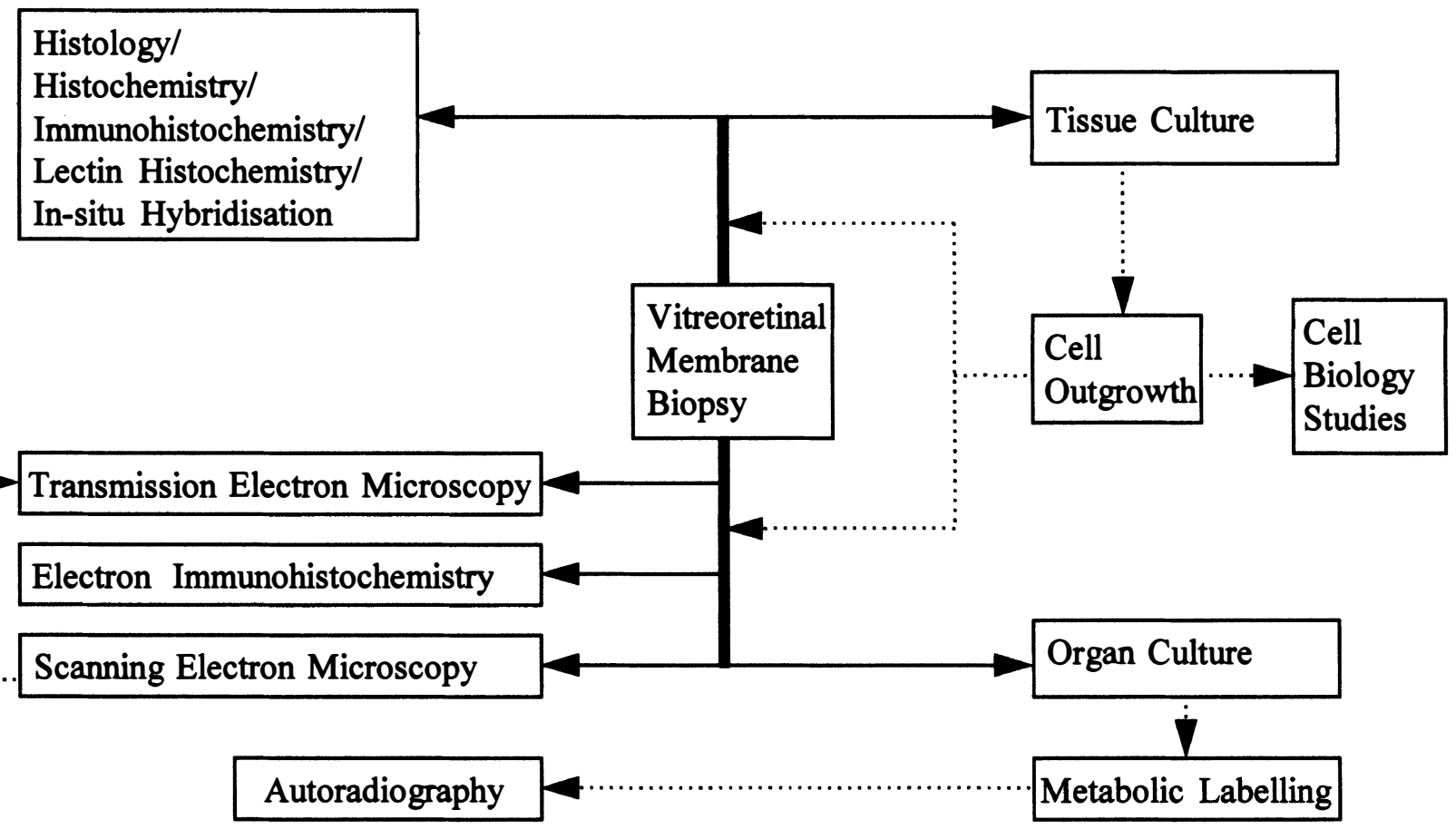

Fig. 1. Diagrammatic representation of some laboratory options available for the investigation of vitreoretinal membrane biopsies. Continuous lines, options with the initial specimen; dotted lines, secondary options.

reasons, studies of membrane composition tend to be morphology-based rather than based on analyses requiring tissue disruption or homogenisation.

Histological, electron microscopic, immunohistochemical and lectin histochemical methods have all been applied to vitreoretinal membranes. To varying degrees, these techniques allow investigation of the presence and location of membrane components such as different cell types, blood vessels, vitreous, retinal fragments and, in the case of epiretinal membranes, the retinal inner limiting lamina (ILL: surgeons may enquire about the presence of ILL in the tissue as the information can help confirm the plane of surgical dissection).

Standard histological methods usually are sufficient to detect blood vessels, ILL and retinal fragments in vitreoretinal membranes. Conversely, histology is often inadequate as a means of identifying the cells in the tissue. Cellular identification may be difficult because ectopic retinal cells, especially retinal pigment epithelial (RPE) cells and glia, in the membranes tend to undergo phenotypic alterations. ${ }^{18-22}$ These changes may be so profound that even electron microscopy cannot resolve the cellular origins of many vitreoretinal membranes. ${ }^{23-25}$ However, fortunately the transformed cells frequently retain cell-type-associated proteins and these proteins (e.g. cytokeratins and glial fibrillary acidic protein in the case of RPE and glia respectively) can be detected immunohistochemically. ${ }^{26,27}$ Thus, we prefer to use immunohistochemistry, rather than electron microscopy, to identify cell types in vitreoretinal membranes. Table 1 lists some of the immunohistochemical markers we have found useful for cell typing in vitreoretinal membranes.

On the other hand, questions regarding the orientation of the ILL are probably most easily addressed by transmission electron microscopy, since this approach allows the smooth vitreous surface of the ILL to be distinguished from the irregular retinal surface. Topographical features of membranes (e.g. the presence of extensive cell sheets at specimen surfaces) can be appreciated by scanning electron microscopy. Scanning microscopy has the added advantage of permitting subsequent transmission electron microscopy on the same specimen (Fig. 1; see also Hiscott et al. ${ }^{28}$ for a method of conducting transmission electron microscopy after scanning electron microscopy on vitreoretinal specimens).

Table 1. Some cell markers useful in the identification of vitreoretinal membrane cell types

\begin{tabular}{ll}
\hline Cell type & Marker \\
\hline Glia & Glial fibrillary acidic protein \\
Retinal pigment epithelia & Cytokeratins \\
Vascular endothelia & von Willebrand factor \\
Inflammatory & CD45 (leucocyte common antigen) \\
Macrophages & CD68 \\
T lymphocytes & CD3 \\
B lymphocytes & CD79A \\
\hline
\end{tabular}




\section{Cellular activities in vitreoretinal membranes}

Sometimes questions regarding membrane cell behaviour or even viability are to be considered. Morphology-based methods again may help here. Thus autoradiography following metabolic labelling, immunohistochemistry and in situ hybridisation can, especially in combination, provide information concerning membrane cell proliferation, synthesis of specific proteins and uptake of metabolic precursors. For example, proliferating cells will take up thymidine while cells synthesising various proteins will incorporate precursor amino acids such as proline, glucosamine or methionine. ${ }^{8}$ Alternatively, it is possible to detect replicating cells in tissue sections with antibodies to certain nuclear proliferation antigens (e.g. Ki 67, MIB1, PCNA) ${ }^{29,30}$ while evidence of the synthesis of specific proteins (e.g. fibronectin) in individual membrane cells can be obtained from tissue sections by the combined use of in situ hybridisation and immunohistochemistry. ${ }^{31,32}$

Cell viability can also be established by placing membranes in tissue culture. ${ }^{33,34}$ If viable cells are present, they will often migrate out of the specimen. Moreover, the origins of these viable cells can be determined immunohistochemically or the cells can be further propagated for in vitro functional studies (Fig. 1). ${ }^{34,35}$

It is apparent that morphological assessment with techniques such as immunohistochemistry, lectin histochemistry, in situ hybridisation and autoradiography can provide much of the information required about vitreoretinal membranes.

\section{Morphological evaluation of vitreoretinal biopsies}

\section{Histology and histochemistry}

Membranes tend to fold or roll up after removal, and thus the maintenance of orientation during processing is very difficult. Attempts to maintain specimen orientation on card, paper or the like have not met with success in our experience and seem to increase the chances of losing the tissues (perhaps because the specimens become dehydrated on paper). Nevertheless, in the case of epiretinal membranes, at least part of the sections should be in a plane perpendicular to the retina (usually the most interesting orientation). Once sectioned, there are often clues as to which surface was in contact with the retina or vitreous. For example, fragments of retina or ILL at one surface of an epiretinal membrane may provide the necessary landmark.

Once acquired, frozen membrane sections or sections of wax- or resin-embedded membranes (see below) can be stained histochemically or immunohistochemically using the same methods that are applied to other tissues in these media.

\section{Preparation and use of frozen sections}

Probably the quickest and simplest histological approach is to produce standard frozen sections of unfixed membranes placed in a small capsule filled with a suitable embedding medium. These sections can then be stained with toluidine blue, haematoxylin and eosin, periodic acid-Schiff, or other stains. Frozen sections can also be used for immunohistochemistry or lectin histochemistry. However, the morphology of membrane frozen sections generally is not as good as that obtained from membranes placed in other embedding agents.

\section{Preparation and use of paraffin sections}

Standard paraffin wax embedding provides good morphology and is satisfactory for most of the histochemical and immunohistochemical procedures required for vitreoretinal membranes.

Membranes fix rapidly because of their thin sheet- or cord-like nature. Routine fixation in 10\% neutral buffered formalin or similar is satisfactory. For the reasons outlined above, it may be difficult to visualise the membrane biopsies throughout processing and there is also a risk that they will be lost in certain automated processors. Small, pale membranes intended for morphological evaluation can usually be seen more easily during processing by coating their surfaces with specimen marking ink such as artist's pigment dissolved in acetone. The ink is applied with a very fine brush with the fixed specimen held in fine forceps. The specimen is wrapped in muslin or filter-type paper to prevent it being washed through holes in automated processor cassettes.

Fragmented specimens can be centrifuged and the resulting cell block supported in agar prior to wax embedding. However, the morphology of fragmented specimens generally is not as good as that of the intact ('peeled') membrane.

Paraffin-embedded membranes typically will yield sections $4 \mu \mathrm{m}$ thick. Although such sections are suitable for immunohistochemistry with a large number of cell and extracellular matrix antibody markers (with or without antigen retrieval methods), some antigens may be irretrievably lost following aldehyde fixation.

\section{Resin sections for light microscopy}

Recently, we have found that problems of morphological and antigenic preservation in vitreoretinal membranes can be circumvented with a method based on the use of glycol methacrylate resin (e.g. JB4, Polysciences) at low temperatures. ${ }^{36}$ These resins also permit tissue sections less than $1 \mu \mathrm{m}$ thick to be produced. Membranes are placed in acetone plus protease inhibitors before being processed into resin at $4{ }^{\circ} \mathrm{C} .{ }^{37}$ The sections provide excellent high-resolution morphology and antigens appear to be well preserved. Moreover, it is possible to acquire several sequential sections through the same cell or group of cells with this method because the sections 
are so thin. However, this resin is not suitable for electron microscopy or, in our experience, for in situ hybridisation (see below).

\section{Immunohistochemistry}

Immunohistochemistry can be conducted on frozen, paraffin or methacrylate resin sections. In our experience, frozen sections are best suited to immunoflourescence studies, whereas paraffin and resin are most suited to immunoenzymatic methods.

The immunohistochemical staining procedure for membranes is no different from that employed for any other tissue. However, given that pigment (often melanin, sometimes haemosiderin) may be prominent in the tissue, the choice of chromogen is important. For example diaminobenzidine, which is frequently used with the immunoperoxidase techniques, yields a brown colour which may be obscured by melanin. Conversely, red chromogens such as 3-amino-9-ethylcarbazole are not so easily confused with melanin.

We have attempted to overcome the problem of pigment in tissues such as vitreoretinal membranes by bleaching the tissue prior to conducting immunohistochemistry. ${ }^{38}$ Although bleaching tended not to interfere with the results of immunohistochemistry for most of the antibodies we investigated, ${ }^{38}$ the procedure was inclined to destroy much of the tissue in individual sections. By contrast, we found that it was easy to discriminate between brown chromogens and melanin granules without the need for bleaching in the semi-thin sections obtained from glycol methacrylate resin-embedded membranes (see above).

\section{Lectin histochemistry}

Lectin histochemistry is based on the affinity of certain sugar-binding proteins and glycoproteins (lectins) for carbohydrate complexes. Such complexes are present on cell membranes and, moreover, vary with cell type. Bopp and colleagues ${ }^{39-41}$ have used lectin histochemistry on sections of vitreoretinal membranes, employing paraformaldehyde fixation and paraffin embedding. These authors used the method to detect RPE cells in the tissue. However, lectin histochemistry has yet to be widely applied to the study of vitreoretinal membranes.

\section{Electron microscopy of vitreoretinal membrane biopsies}

For scanning and transmission electron microscopy, 2\% or $3 \%$ glutaraldehyde in Sorensen's phosphate buffer is often employed as primary fixative before postfixation and dehydration. The dehydrated specimens are infiltrated with resin for transmission electron microscopy, whereas membranes for scanning electron microscopy are critical-point-dried and gold coated. After scanning studies are complete, scanned membranes can be 'recycled' for transmission electron microscopy by resin infiltration (Fig. 1.). ${ }^{28}$
Electron microscopic immunohistochemistry (electron immunohistochemistry)

Pre- and post-embedding electron immunohistochemical techniques have been employed in the study of epiretinal membranes. ${ }^{42-44}$ In general, more gentle fixation (e.g. with $4 \%$ paraformaldehyde plus $0.1 \%$ glutaraldehyde) is required for electron immunohistochemistry than for standard transmission microscopy of vitreoretinal biopsies. Vinores and coworkers $^{42,43}$ and Casaroli-Marano and colleagues ${ }^{44}$ have demonstrated that it is possible to identify cell types in thin sections of epiretinal membranes using pre- and post-embedding methods respectively. However, some dedifferentiated RPE in epiretinal membranes subjected to postembedding electron immunohistochemistry appears to coexpress both RPE and glial markers, and thus this method may require a double or even triple immunostaining approach. ${ }^{43,44}$

\section{Autoradiography}

Metabolic labelling can be conducted in a Leighton tube with the specimen in a small (1-2 ml) volume of culture fluid. We have used a standard culture medium with serum and glutamine. ${ }^{8}$ The radiolabelled substrate is added to the organ culture and incubation conducted for $24 \mathrm{~h}$ at $37^{\circ} \mathrm{C}$. The specimens are then fixed and processed into paraffin wax or an electron microscopy resin (we prefer to use semithin sections of resin-embedded specimens for autoradiography). ${ }^{8}$ Sections are placed on subslides (made with a section adhesive such as gelatine) before coating with a nuclear emulsion. After development, the sections are counterstained and sites of label incorporation evaluated.

\section{In situ hybridisation}

We have successfully conducted in situ hybridisation with single-stranded RNA probes on formalin-fixed, paraffin-embedded membranes. ${ }^{31,32,45}$ As with immunohistochemistry, the in situ hybridisation procedure for membranes is no different from that employed for any other tissue.

For heavily pigmented specimens, we found methods based on radiolabelled probes and autoradiography superior to techniques reliant on immunohistochemical probe detection. ${ }^{31,45}$ The silver grains produced by the action of the radiolabelled probes on the autoradiographic emulsion can be visualised as white dots against a dark background by epipolarisation microscopy. This method renders localisation of hybridisation sites easy against pigment (which is 'lost' in the dark background). Moreover, it is possible to count the numbers of silver grains over individual cells, thus enabling a semi-quantitative evaluation to be undertaken. $^{31}$ 


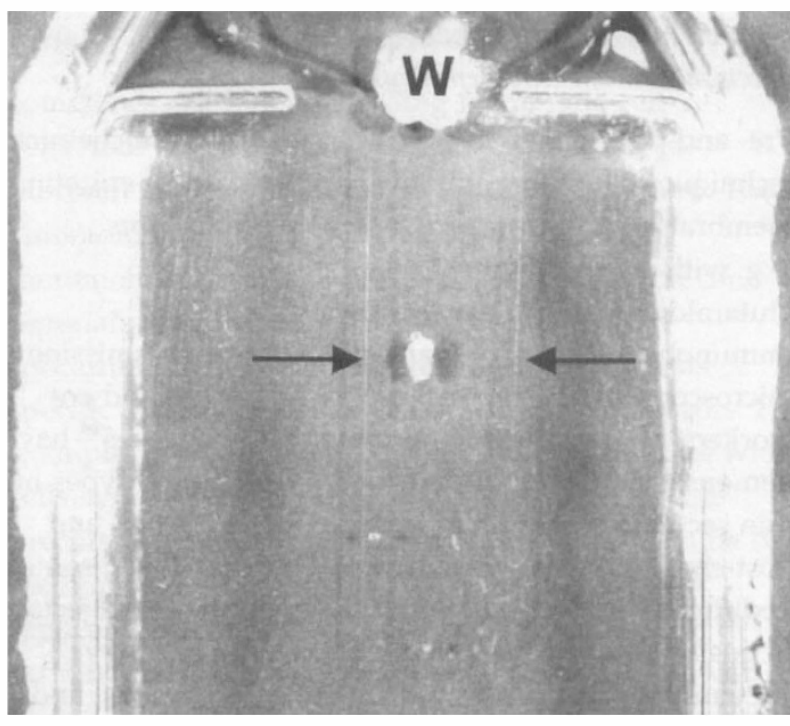

Fig. 2. The tissue culture of vitreoretinal membranes. A glass coverslip (arrows) holds the specimen (which can be seen in the centre of the line between the arrows) in position on the base of a tissue culture flask. The coverslip is maintained in place over the specimen by a bead of wax $(W)$. Tissue culture medium is added to the preparation when the wax is solid.

\section{In vitro studies of vitreoretinal membranes}

Most vitreoretinal membranes are too small to divide up or homogenise, so specimens intended for tissue culture are usually best handled intact.

Cellular outgrowths can be obtained from membranes in tissue culture. ${ }^{34}$ Initial attempts to propagate cells depended on embedding the specimen in chick clot.

However, much more succes was obtained by trapping the membrane between the base of a culture flask and a sterile glass coverslip, the latter held in place by a drop of beeswax at one end (Fig. 2). This second method removes the obstacle of the clot from the cell outgrowth and, moreover, creates a microenvironment between coverslip and culture flask which may permit accumulation of growth factors etc., and hence augment the early outgrowth.

Our original tissue culture studies were aimed at determining membrane cell viability and origins, the latter using methods such as locomotory characteristics of the cellular outgrowth and immunofluorescence investigations of the intermediate filament expression of these cells. ${ }^{34}$ Subsequently, we were able to employ the cell outgrowth in primary tissue culture to examine the behaviour of membrane cells in more detail. For example, it was possible to study the contractile abilities of individual cells from the membranes using an ATP contraction assay, as well as observing cell locomotory patterns. ${ }^{35}$

\section{Conditions which may give rise to periretinal mem- branes: features of diagnostic help}

The composition of vitreoretinal membranes is very variable, and often reflects the cause of the process. The principal cellular components of typical epiretinal and subretinal membranes complicating various conditions are presented in Tables 2 and 3 respectively. Although the nature of the original disease is usually obvious from the clinical features (see above), occasionally examination of the specimen provides information about the aetiology of a condition.

Epiretinal membranes (or their posterior hyaloid extensions) which arise in the presence of an ischaemic inner retina (e.g. in proliferative diabetic retinopathy, central or branch retinal vein occlusion) characteristically have a major vascular element (Table 2, Fig. 3). Indeed, these new vessels tend to form vascular networks in the vitreous cortex. ${ }^{5}$ In contrast, only about $10-15 \%$ of epiretinal membranes which complicate

rhegmatogenous retinal detachment or its surgery (that is PVR membranes) have blood vessels and, furthermore, this vascular element typically is limited to a few capillaries (Table 2, Fig. 3) (reviewed by Hiscott and Grierson ${ }^{46}$ ). An exception to this rule is the PVR membrane involving the ciliary processes or posterior iris ('anterior PVR membrane'), which may have a substantial vascular element. ${ }^{47}$ Blood vessels may also be found in vitreoretinal membranes of other conditions such as Eales' disease and some cases of uveitis. ${ }^{48}$

RPE cells tend to be abundant in epiretinal membranes which have arisen in the presence of a retinal hole (including retinal holes following ocular trauma). Not surprisingly, such RPE-rich membranes are most often encountered in PVR (Table 2, Fig. 3). However, it is worth remembering that retinal holes can be produced secondary to other pathology such as retinal necrosis or traction from pre-existing membranes. Thus membranes from eyes with combined traction rhegmatogenous detachments in proliferative diabetic retinopathy may also contain numerous RPE cells. ${ }^{49}$ Equally, iatrogenic

Table 2. The aetiology and cellular composition of epiretinal membrane biopsies

\begin{tabular}{|c|c|c|c|c|c|}
\hline & Blood vessels & Glial cells & RPE cells & $\begin{array}{c}\text { Fibroblastic } \\
\text { cells }\end{array}$ & $\begin{array}{c}\text { Inflammatory } \\
\text { cells }\end{array}$ \\
\hline Ischaemic retinopathies, including PDR & ++ & + & $-1+$ & ++ & + \\
\hline Retinal hole, including (posterior) PVR & $-1+$ & + & ++ & ++ & + \\
\hline Inflammation & $-1+$ & + & $?$ & $?$ & ++ \\
\hline Idiopathic & $-1+$ & ++ & $-/+$ & ++ & + \\
\hline $\begin{array}{l}\text { Following posterior vitreous detachment } \\
\text { (e.g. 'simple' and 'surface wrinkling } \\
\text { retinopathy' membranes) }\end{array}$ & $-1+$ & $++^{a}$ & $-1+$ & $-1+$ & $-1+$ \\
\hline
\end{tabular}

${ }^{a}$ Characteristically only cell type in membrane.

RPE, retinal pigment epithelial; PDR, proliferative diabetic retinopathy; PVR, proliferative vitreoretinopathy.

++ , usually abundant; + , usually present, but not prominent; $-/+$, usually absent, if present usually not abundant; ?, contribution uncertain. 
Table 3. The aetiology and cellular composition of subretinal membrane biopsies

\begin{tabular}{|c|c|c|c|c|c|}
\hline & Blood vessels & Glial cells & RPE cells & Fibroblastic cells & Inflammatory cells \\
\hline PVR & $-1+$ & + & ++ & ++ or + & + \\
\hline Disciform-type & ++ & $?$ & + & ++ or + & + \\
\hline
\end{tabular}

RPE, retinal pigment epithelial; PVR, proliferative vitreoretinopathy.

++ , usually abundant; + , usually present, but not prominent; $-/+$, usually absent, if present usually not abundant; ?, contribution uncertain.

retinotomies or retinal detachments may lead to PVR. In such cases it is important that the surgeon informs the pathologist of the original indication for surgery. For example, in the case of PVR complicating local or endoresection of uveal melanoma, tumour cells could be present alongside RPE cells in the vitreoretinal membranes.

Problematic subretinal membranes occur in about $13 \%$ of all cases of PVR. ${ }^{50}$ These membranes tend to form bands rather than sheets beneath the neuroretina and may be excised during PVR surgery (Fig. 4). ${ }^{51,52}$ As with PVR epiretinal membranes, they are usually avascular and RPE-rich. ${ }^{53,54}$ By contrast, disciform-type subretinal membranes (such as may complicate ARMD, angioid streaks, presumed ocular histoplasmosis syndrome (POHS), etc.) are primarily vascular in nature (Table 3, Fig. 4), the vessels arising from the choroid (see, for example, reviews by $\operatorname{Coscas}^{55}$ and Garner and colleagues ${ }^{56}$ ). Nevertheless, these vascular membranes may still have a distinct RPE component (Fig. 4). Thus RPE may contribute to the fibrous element of neovascular membranes and, in conditions like POHS, form layers over the membrane surfaces. ${ }^{57}$ Indeed, the presence of RPE layers at neovascular membrane surfaces may have significance for the outcome of surgery (excision of subretinal neovascular membrane has an excellent visual outcome in POHS but not in ARMD). ${ }^{58,59}$ It is suggested that RPE layers around the membrane in POHS reflect growth of the vessels in the subsensory retinal space (in ARMD the vessels tend to grow beneath the RPE). ${ }^{60}$ Thus native RPE is thought to be available for reapproximation with photoreceptors following excision of the membrane in POHS (but not in ARMD) ${ }^{60}$ and so the RPE layer may be indicative of a favourable prognosis and the subject of the surgeon's questions.

Glial cells are frequently present in vitreoretinal membranes, but tend to be a relatively minor component of PVR epi- and sub-retinal membranes as well as of PDR membranes. Conversely, 'simple' and 'surface wrinkling retinopathy' epiretinal membranes are usually composed solely of glia (Table 2, Fig. 3). ${ }^{61,62}$ Indeed these glial membranes are the most frequent type of epiretinal membrane, perhaps because they represent a local response to ILL damage after age-related posterior vitreous detachment or other age-related pathology. ${ }^{61}$ However, these types of membrane produce minimal symptoms and thus are rarely removed for pathological analysis. Glial cells have been reported as major components of post-inflammatory and symptomatic idiopathic membranes, ${ }^{48,63}$ and in vitreoretinal tissues associated with other conditions such as macular holes and retinitis pigmentosa. ${ }^{15,64,65}$

Fibroblast- or myofibroblast-like cells are almost ubiquitous in vitreoretinal membranes (except in the purely glial membranes described above) and therefore not usually helpful diagnostically. ${ }^{66}$

In general, inflammatory cells, like glia, only form a minor component of many vitreoretinal membranes (including PVR epi- and sub-retinal membranes) being represented by macrophages and a few lymphocytes. ${ }^{10,66,67}$ Nevertheless, inflammatory cells may be a prominent component of membranes arising in the presence of intraocular inflammation (Fig. 4, Table 2). ${ }^{8}$ For the most part, the cells found in membranes complicating chronic uveitis are mononuclear and include lymphocytes, plasma cells, monocytes and macrophages (Fig. 4). Polymorphs are rarely found in vitreoretinal membranes irrespective of their aetiology, except in the presence of acute inflammation. In this latter case, the membranes tend to be friable with abundant fibrin and scattered polymorphs (Fig. 4).

Except for 'fibrinous' membranes, which may arise in acute intraocular inflammation but more typically form in the eye during vitrectomy, ${ }^{68}$ the principal extracellular component of membranes is collagen. A range of collagen subtypes are found in vitreoretinal membranes and the relative amounts of the subtypes may reflect the aetiology. Because PVR usually occurs in eyes which have undergone posterior vitreous detachment during the development of rhegmatogenous retinal detachment, PVR membranes may have little collagen type II (although, forming directly on the retinal surface, they may have abundant ILL (Fig. 3); ILL is also a major component of membranes associated with idiopathic macular holes). ${ }^{64,69}$ Conversely, collagen type II may be a prominent component of PDR membranes where the fibrovascular proliferation has incorporated the vitreous cortex within the epiretinal tissue (Fig. 3). ${ }^{70}$

With time, the collagenous component of most vitreoretinal membranes tends to become more prominent whereas some of the cells degenerate. ${ }^{8}$ Histologically, the degenerating cells may exhibit small intracellular vacuoles. Larger intra- and extra-cellular spherical spaces, often with quite marked size variation, are also seen when the membrane has arisen in the presence of a tamponade agent such as silicone oil (Fig. 4). ${ }^{71}$ Thus the finding of many such 'vacuoles' should alert the pathologist to the possibility that a tamponade agent has been used. 

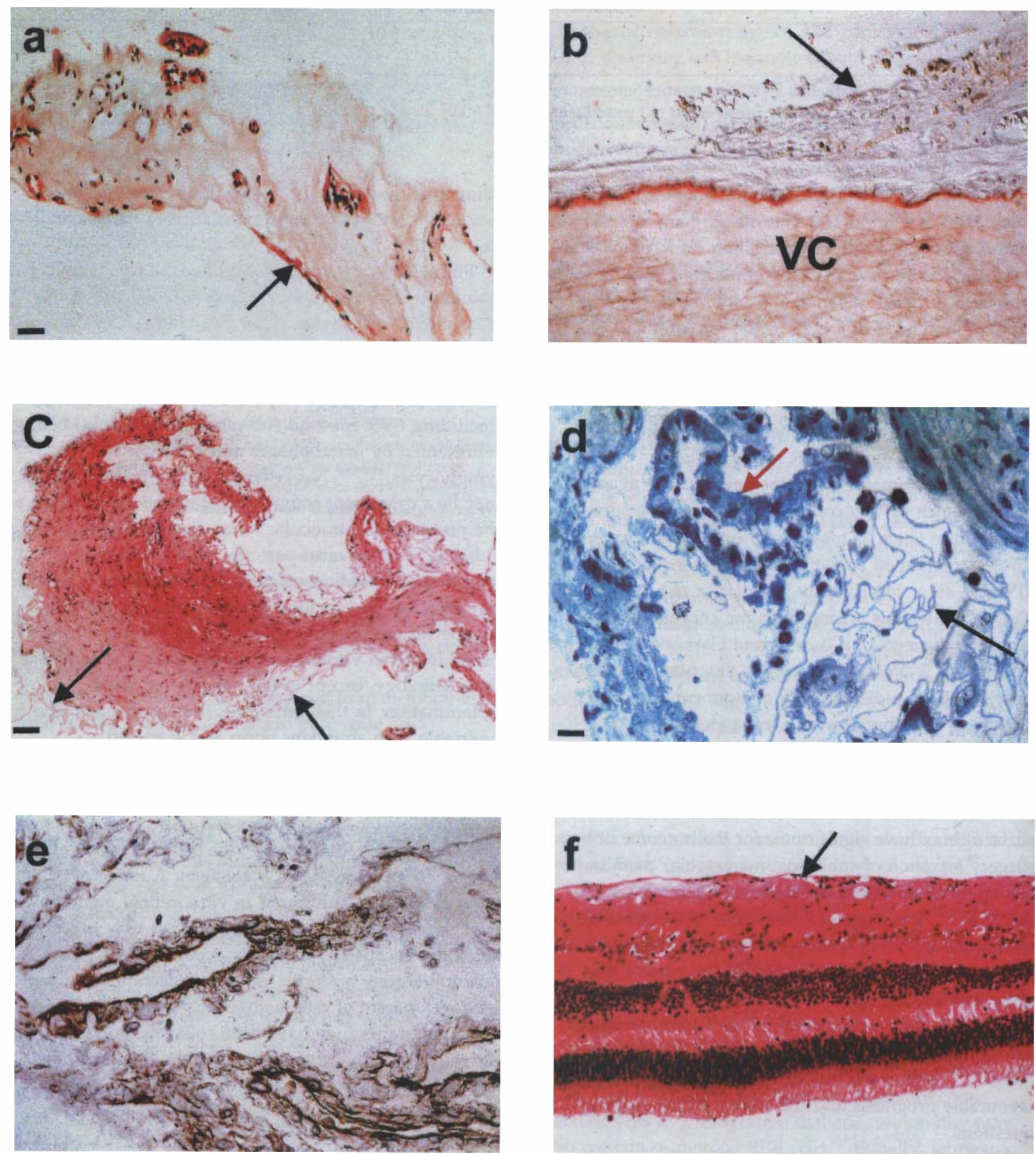

Fig. 3. (a), (b) Sections through membranes complicating proliferative diabetic retinopathy (PDR). (a) The specimen consists of fibrovascular tissue with a layer of glial-like cells at one edge (arrow), and is typical of PDR epiretinal and posterior hyaloid membranes (paraffin-embedded vitrectomy specimen, haematoxylin and eosin). (b) The section (from a paraffin-embedded eye) has been stained with the immunoperoxidase technique for collagen type II. The membrane (arrow) has formed in close proximity to the vitreous cortex (VC), which is demonstrated red by its immunoreactivity for collagen II (differential interference contrast microscopy). (c)-(e) Sections through excised proliferative vitreoretinopathy (PVR) membranes. All three PVR epiretinal membranes are avascular. (c) The specimen consists chiefly of fibrocellular tissue. Abundant inner limiting lamina (ILL) from the retinal surface is present (arrows) (paraffin section, haematoxylin and eosin). (d) Semi-thin section of electron microscopy (EM) resin embedded membrane (toluidine blue). Much ILL can again be seen (black arrow). The prominent cell layer may be glial or retinal pigment epithelial (RPE) in origin (red arrow). (e) Semi-thin section from a specimen embedded in a light microscopy resin stained with the immunoperoxidase method for cytokeratins (brown reaction product) to demonstrate RPE cells (haematoxylin counterstain). Most of the cells are RPE in origin. (f) Section (from a paraffin-embedded eye) through neuroretina with a simple-type epiretinal membrane (arrow). The retinal surface is mildly wrinkled but no full-thickness retinal folding is seen (haematoxylin and eosin). Scale bars represent: (a) $50 \mu m$; (b) magnification as in (a); (c) $100 \mu \mathrm{m}$; (d) $20 \mu \mathrm{m}$; (e) magnification as in (d); (f) magnification as in (c). 

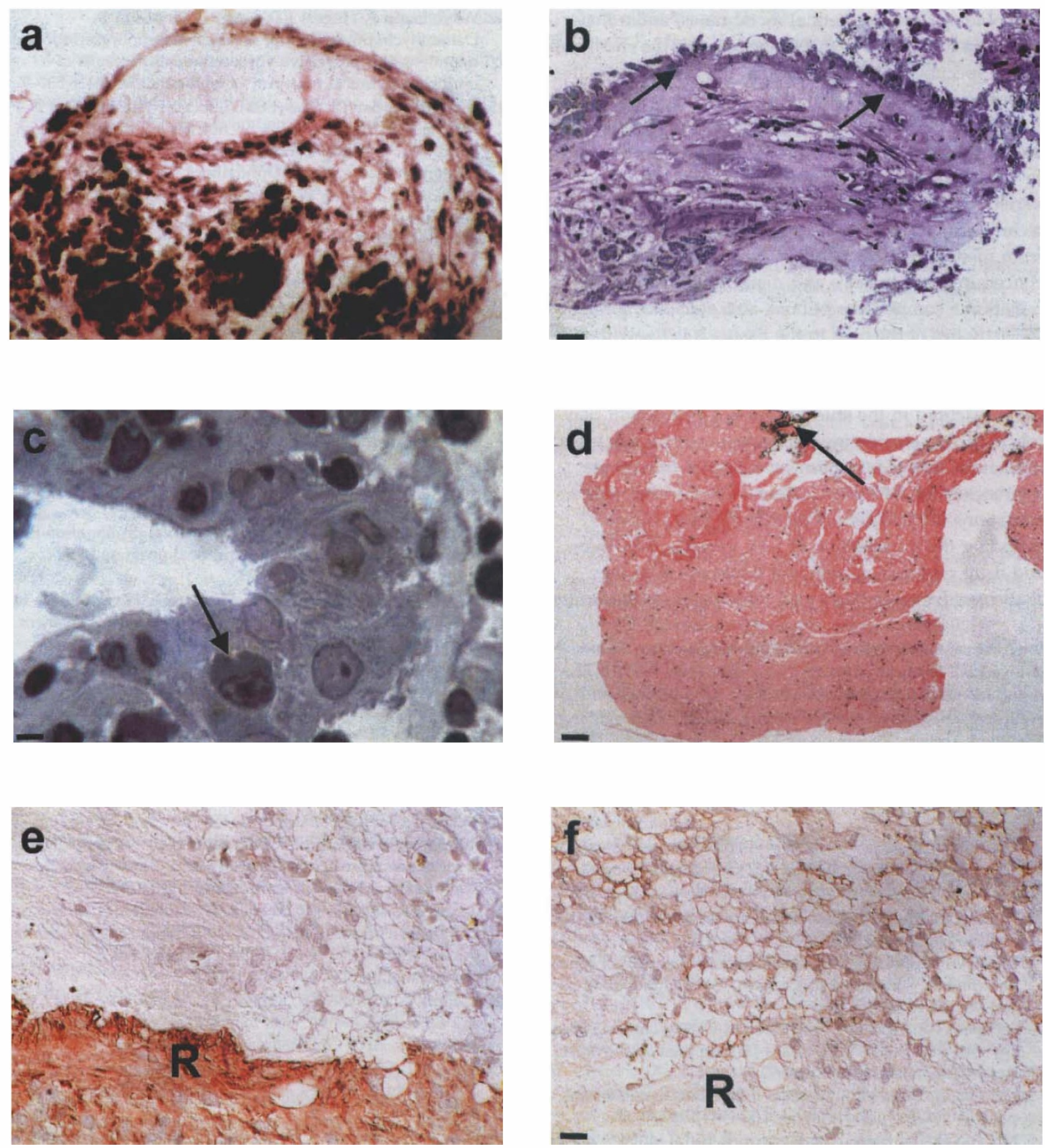

Fig. 4. (a), (b) Excised subretinal membranes complicating proliferative vitreoretinopathy (PVR) and posterior uveitis of unknown cause respectively. (a) The membrane has formed a subretinal band which consists of pigmented cells in delicate avascular fibrous tissue (paraffin section, haematoxylin and eosin). (b) Semi-thin section from EM resin-embedded tissue (toluidine blue). The bulk of the specimen consists of dense fibrovascular tissue with a layer of RPE-like cells at a surface (arrows). (c), (d) Excised epiretinal membranes from patients with chronic posterior uveitis and acute retinal necrosis, respectively. (c) The membrane contains numerous mononuclear inflammatory cells including a plasma cell (arrow) (semi-thin section of EM resin-embedded tissue, toluidine blue). (d) The specimen consists of fibrinous material containing scattered polymorphs. The ink used to aid visualisation of the tissue during processing can be seen (arrow) (paraffin section, haematoxylin and eosin). (e), (f) Sections through an excised, paraffin-embedded PVR membrane which has formed behind silicone oil. The sections are stained with the immunoperoxidase method for glial fibrillary acidic protein (glial marker) and cytokeratins (RPE marker) respectively (red reaction product, haematoxylin counterstain). (e) A fragment of glial-rich retinal tissue is present in the biopsy (R). (f) Numerous vacuolated RPE cells, presumed to have contained silicone oil, are seen in the epiretinal membrane. Scale bars represent: (b) and (f) $25 \mu \mathrm{m} ;(a)$ and (e) magnification as in (b) and (f); (c) $10 \mu \mathrm{m} ;(d) 150 \mu \mathrm{m}$. 


\section{Conclusions and the future}

There is still much that we do not understand about the pathobiology of vitreoretinal membranes, and a major handicap for studies of this tissue remains the small bulk of the specimens. Nevertheless, in the last 20 years the information obtained from biopsies of these tissues has contributed to many refinements in vitreoretinal surgery and to the development of medical regimens as adjuncts to vitreous surgery. Moreover, the application of a variety of staining, immunological and molecular techniques to membrane sections and to cells cultured from membranes can not only provide information concerning the presence and distribution of various membrane components but can also elucidate some of the activities of the cells in the tissue. It is likely that the use of more sensitive cell and molecular biological methods (such as in situ reverse transcription polymerase chain reaction) in the study of these biopsies will play a role in further elucidating the formation of the tissue and, ultimately, in the development of logical therapeutic approaches for their management. On the other hand, alterations in vitreoretinal membrane management, including the introduction of new vitreous substitutes and drug reservoir agents, will doubtless raise new challenges for researchers and pathologists in the future.

Vitreoretinal Research in the Unit of Ophthalmology, University of Liverpool has been supported by Guide Dogs For The Blind Association, NHS Executive North West R\&D Directorate, Wellcome Trust, Royal College of Surgeons of Edinburgh and The Blind Asylum, Research into Eye Disease, Sir Jules Thorn Charitable Trust, St Paul's Foundation for the Prevention of Blindness, and the Dunhill Medical Trust. Mr Alan Williams provided photographic assistance.

\section{References}

1. Parsons JH. The pathology of the eye, vol 2. London: Hodder and Stoughton, 1905:542-600.

2. Cibis PA. Recent methods in the surgical treatment of retinal detachment: intravitreal procedures. Trans Ophthalmol Soc UK 1965;85:111-26.

3. Schepens CL. Clinical and research aspects of subtotal opensky vitrectomy. XXXVII Edward Jackson memorial lecture. Am J Ophthalmol 1993;91:143-71.

4. McLeod D, Marshall J, Grierson I. Epimacular membrane peeling. Trans Ophthalmol Soc UK 1981;101:170-80.

5. McLeod D. The vitreous and its disorders. In: Miller S, editor. Clinical ophthalmology. Bristol: Wright, 1987:258-74.

6. Grierson I, Mazure A, Hogg P, Hiscott P, Sheridan C, Wong D. Non-vascular vitreoretinopathy: the cells and the cellular basis of contraction. Eye 1996;10:671-84.

7. Grierson I, Hiscott P, Sheridan C, Tuglu I. The pigment epithelium: friend and foe of the retina. Proc R Microsc Soc 1997;32:161-70.

8. Hiscott PS, Grierson I, McLeod D. The natural history of epiretinal membranes: a quantitative, immunohistochemical and autoradiographic study. Br J Ophthalmol 1985;69:810-23.

9. Gilbert C, Hiscott PS, Unger W, Grierson I, McLeod D. Inflammation and the formation of epiretinal membranes. Eye 1988;2(Suppl):S140-56.

10. Chateris D, Hiscott P, Grierson I, Lightman S. Proliferative vitreoretinopathy: lymphocytes in epiretinal membranes. Ophthalmology 1992;99:1364-7.
11. Charteris DG. Proliferative vitreoretinopathy: pathobiology, surgical management, and adjunctive treatment. Br J Ophthalmol 1995;79:953-60.

12. Wiedemann P, Hilgers RD, Bauer P, Heimann K. Daunomycin Study Group. Adjunctive daunorubicin in the treatment of proliferative vitreoretinopathy: results of a multicenter clinical trial. Am J Ophthalmol 1998;126:550-9.

13. Pena RA, Jerdan JA, Glaser BM. Effects of TGF-beta and TGFbeta neutralizing antibodies on fibroblast-induced collagen gel contraction: implications for proliferative vitreoretinopathy. Invest Ophthalmol Vis Sci 1994;35:2804-8.

14. Choudhury P, Chen W, Hunt RC. Production of plateletderived growth factor by interleukin-1 beta and transforming growth factor-beta-stimulated retinal pigment epithelial cells leads to contraction of collagen gels. Invest Ophthalmol Vis Sci 1997;38:824-33.

15. Ezra E, Munro PM, Charteris DG, Aylward WG, Luthert PJ, Gregor ZJ. Macular hole opercula: ultrastructural features and clinicopathological correlation. Arch Ophthalmol 1997;115:1381-7.

16. Grierson I, Hiscott PS, Hitchins C, McKechnie NM, White VA, McLeod D. Which cells are involved in the formation of epiretinal membranes? Semin Ophthalmol 1987;2:99-109.

17. Hiscott P, Sheridan C, Magee R, Grierson I. Matrix and the retinal pigment epithelium in proliferative retinal disease. Prog Retinal Eye Res 1999;18:167-90.

18. Machemer R, Laqua H. Pigment epithelial proliferation in retinal detachment (massive periretinal proliferation). Am J Ophthalmol 1975;80:1-23.

19. Mandelcorn MS, Machemer R, Fineberg E, Hersch SB. Proliferation and metaplasia of intravitreal retinal pigment epithelium cell autotransplants. Am J Ophthalmol 1975;80:227-37.

20. Mueller-Jensen K, Machemer R, Azarnia R. Autotransplantation of retinal pigment epithelial cells in intravitreal diffusion chamber. Am J Ophthalmol 1975;80:530-7.

21. Machemer R. Pathogenesis and classification of massive periretinal proliferation. Br J Ophthalmol 1978;62:737-47.

22. Vidaurri-Leal J, Hohman R, Glaser BM. Effect of vitreous on morphologic characteristics of retinal pigment epithelial cells: a new approach to the study of proliferative vitreoretinopathy. Arch Ophthalmol 1984;102:1220-3.

23. Green WR, Kenyon KR, Michels RG, Gilbert HD, de la Cruz ZC. Ultrastructure of epiretinal membranes causing macular pucker after retinal re-attachment surgery. Trans Ophthalmol Soc UK 1979;99:65-77.

24. Kampik A, Kenyon KR, Michels RG, Green WR, de la Cruz ZC. Epiretinal and vitreous membranes: comparative study of 56 cases. Arch Ophthalmol 1981;99:1445-54.

25. Trese MT, Chandler DB, Machemer R. Macular pucker. II. Ultrastructure. Graefes Arch Clin Exp Ophthalmol 1983;221:16-26.

26. Hiscott PS, Grierson I, Trombetta CJ, Rahi AHS, Marshall J, McLeod D. Retinal and epiretinal glia: an immunohistochemical study. Br J Ophthalmol 1984;68:698-707.

27. Hiscott PS, Grierson I, McLeod D. Retinal pigment epithelial cells in epiretinal membranes: an immunohistochemical study. Br J Ophthalmol 1984;68:708-15.

28. Hiscott P, Rosen P, Cooling RJ, Garner A. The pathology of abortive neovascular outgrowths from the retina. Graefes Arch Clin Exp Ophthalmol 1992;230:531-6.

29. Heidenkummer HP, Kampik A. Proliferative activity and immunohistochemical cell differentiation in human epiretinal membranes. Ger J Ophthalmol 1992;1:170-5.

30. Heidenkummer HP, Kampik A, Petrovski B. Proliferative activity in epiretinal membranes: the use of the monoclonal antibody Ki-67 in proliferative vitreoretinal diseases. Retina 1992;12:52-8. 
31. Hiscott P, Waller HA, Butler MG, Grierson I, Scott DL. Local production of fibronectin by ectopic human retinal cells. Cell Tissue Res 1992;267:185-92.

32. Hiscott P, Waller HA, Grierson I, Butler MG, Scott DL. The extracellular matrix of reparative tissue in the vitreous: fibronectin synthesis in diabetic retinopathy membranes. Eye 1993;7:288-92.

33. Newsome DA, Rodrigues MM, Machemer R. Human massive periretinal proliferation: in vitro characteristics of cellular components. Arch Ophthalmol 1981;99:873-80.

34. Hiscott PS, Grierson I, Hitchings C, Rahi AHS, McLeod D. Epiretinal membranes in vitro. Trans Ophthalmol Soc UK 1983;103:89-102.

35. Jiang DY, Hiscott PS, Grierson I, McLeod D. Some features of cells grown from epiretinal membranes in primary culture with particular reference to their contractile properties. Br J Ophthalmol 1987;72:116-26.

36. Kanawati C, Wong D, Hiscott P, Sheridan C, McGalliard J. 'En bloc' dissection of epiretinal membranes using aspiration delamination. Eye 1996;10:47-52.

37. Uhr G, Giebel J, Schwenk M. Combined lectin binding and PAS/alcian blue staining in glycol methacrylate sections. Biotech Histochem 1993;68:240-5.

38. Alexander RA, Hiscott PS, Hart R, Grierson I. Effect of melanin bleaching on immunoperoxidase with reference to ocular tissues and lesions. Med Lab Sci 1986;43:121-7.

39. Bopp S, el Hifnawi ES, Laqua H. Localization of lectinbinding sites on retinal pigment epithelium and photoreceptor cells of the human eye. Fortschr Ophthalmol 1989;86:515-8.

40. Bopp S, el Hifnawi ES, Laqua H. Lectin histochemical investigations on the retinal pigment epithelium after photocoagulation. Fortschr Ophthalmol 1990;87:351-4.

41. Bopp S, el Hifnawi ES, Laqua H. Lectin binding pattern in human retinal pigment epithelium. Anat Anz 1992;174:29-85.

42. Vinores SA, Campochiaro PA, Conway BP. Ultrastructural and electron-immunocytochemical characterisation of cells in epiretinal membranes. Invest Ophthalmol Vis Sci 1990;31:14-28.

43. Vinores SA, Van Niel E, Kim HJ, Campochiaro PA. Simultaneous expression of keratin and glial fibrillary acidic protein by the same cells in epiretinal membranes. Invest Ophthalmol Vis Sci 1992;33:3361-6.

44. Casaroli-Marano RP, Pagan R, Vilaro S Epithelial-mesenchymal transition in proliferative vitreoretinopathy: intermediate filament protein expression in retinal pigment epithelial cells. Invest Ophthalmol Vis Sci 1999;40:2062-72.

45. Hiscott P, Waller HA, Grierson I, Butler MG, Scott DL, Gregor Z, et al. Fibronectin synthesis in subretinal membranes of proliferative vitreoretinopathy. Br J Ophthalmol 1992;76:486-90.

46. Hiscott P, Grierson I. Retinal detachment. In: Garner A, Klintworth GK, editors. Pathobiology of ocular disease: a dynamic approach. 2nd ed. New York: Marcel Dekker, 1994:675-700.

47. Elner SG, Elner VM, Diaz-Rohena R, Freeman HM, Tolentino FI, Albert DM. Anterior proliferative vitreoretinopathy; clinical, light microscopic, and ultrastructural findings. Ophthalmology 1988;95:1349-57.

48. Green WR, Kincaid MC, Michels RG, Pederson JE, Kenyon KR, Maumenee AE. Pars planitis. Trans Ophthalmol Soc UK 1981;101:361-7.

49. Hiscott P, Gray R, Grierson I, Gregor Z. Cytokeratincontaining cells in proliferative diabetic retinopathy membranes. Br J Ophthalmol 1994;78:219-22.

50. Lewis H, Aaberg TM, Abrams GW, McDonald HR, Williams GA, Mieler WF. Subretinal membranes in proliferative vitreoretinopathy. Ophthalmology 1989;96:1403-15.
51. Federman JL, Foldberg R, Ridley M, Arbizo VA. Subretinal cellular bands. Trans Am Ophthalmol Soc 1983;81:172-9.

52. Sternberg P, Machemer R. Subretinal proliferation. Am J Ophthalmol 1984;98:456-62.

53. Hiscott P, Morino I, Alexander R, Grierson I, Gregor Z. Cellular components of subretinal membranes in proliferative vitreoretinopathy. Eye 1989;3:606-10.

54. Garcia-Arumi J, Corcostegui B, Tallada N. Subretinal membranes in proliferative vitreoretinopathy: an immunohistochemical study. Retina 1992;12:S55-9.

55. Coscas G. Montgomery lecture. Subretinal neovascularisation in senile macular degeneration. Eye 1987;1:364-78.

56. Garner A, Sarks S, Sarks JP. Degenerative and related disorders of the retina and choroid. In: Garner A, Klintworth GK, editors. Pathobiology of ocular disease: a dynamic approach. 2nd ed. New York: Marcel Dekker, 1994:631-74.

57. Saxe SJ, Grossniklaus HE, Lopez PF, Lambert HM, Sternberg P, L'Hernault N. Ultrastructural features of surgically excised subretinal neovascular membranes in the ocular histoplasmosis syndrome. Arch Ophthalmol 1993;111:88-95.

58. Thomas MA, Grand G, Williams DF, Lee CM, Pesin SR, Lowe MA. Surgical management of subfoveal choroidal neovascularisation. Ophthalmology 1992;99:952-68.

59. Berger AS, Kaplan HJ. Clinical experience with the surgical removal of subfoveal neovascular membranes. Ophthalmology 1992;99:969-76.

60. Gass JD. Biomicroscopic and histopathologic considerations regarding the feasibility of surgical excision of subfoveal neovascular membranes. Am J Ophthalmol 1994;118:285-98.

61. Foos RY. Vitreoretinal juncture: simple epiretinal membranes. Graefes Arch Clin Exp Ophthalmol 1974;189:231-50.

62. Roth AM, Foos RY. Surface wrinkling retinopathy in eyes enucleated at autopsy. Trans Am Acad Ophthalmol Otolaryngol 1971;75:1047-58.

63. Kampik A, Green WR, Michels RG, Nase PK. Ultrastructural features of progressive idiopathic epiretinal membrane removed by vitreous surgery. Am J Ophthalmol 1980;90:797-809.

64. Heidenkummer HP, Kampik A. Morphologic analysis of epiretinal membranes in surgically treated idiopathic macular foramina: results of light and electron microscopy. Ophthalmologe 1996;93:675-9.

65. Szamier RB. Ultrastructural features of the preretinal membrane in retinitis pigmentosa. Invest Ophthalmol Vis Sci 1981;21:227-36.

66. Michels RG. A clinical and histopathological study of epiretinal membranes affecting the macula and removed by vitreous surgery. Trans Am Ophthalmol Soc 1982;80:580-656.

67. Chateris DG, Hiscott P, Robey HL, Gregor ZJ, Lightman SL, Grierson I. Proliferative vitreoretinopathy: lymphocytes in subretinal membranes. Ophthalmology 1993;100:43-6.

68. Pecson BD, Wolfe JK, Gipson IK, Hirose T, Buznet SM, Schepens CL. Characterization of membranes removed during open-sky vitrectomy. Invest Ophthalmol Vis Sci 1983;24:1382-9.

69. Morino I, Hiscott P, McKechnie N, Grierson I. Variation in epiretinal membrane components with clinical duration of the proliferative tissue. Br J Ophthalmol 1990;74:393-9.

70. Schwartz SD, Alexander R, Hiscott P, Gregor ZJ. Recognition of vitreoschisis in proliferative diabetic retinopathy: a useful landmark in vitrectomy for diabetic traction retinal detachment. Ophthalmology 1996;103:323-8.

71. Leaver PK, Grey RHB, Garner A. Silicone oil injection in the treatment of massive preretinal retraction. II. Late complications in 93 eyes. Br J Ophthalmol 1979;63:361-7. 